University of Wollongong

Research Online

Faculty of Science, Medicine and Health -

Papers: part A

Faculty of Science, Medicine and Health

$1-1-2012$

\title{
Selective transport of Cadmium by PVC/Aliquat 336 polymer inclusion membranes (PIMs): the role of membrane composition and solution chemistry
}

\author{
Sandra Adelung \\ University of Wollongong \\ Burkhard Lohrengel \\ Heilbronn University \\ Long Duc Nghiem \\ University of Wollongong, longn@uow.edu.au
}

Follow this and additional works at: https://ro.uow.edu.au/smhpapers

Part of the Medicine and Health Sciences Commons, and the Social and Behavioral Sciences

\section{Commons}

\section{Recommended Citation}

Adelung, Sandra; Lohrengel, Burkhard; and Nghiem, Long Duc, "Selective transport of Cadmium by PVC/ Aliquat 336 polymer inclusion membranes (PIMs): the role of membrane composition and solution chemistry" (2012). Faculty of Science, Medicine and Health - Papers: part A. 347.

https://ro.uow.edu.au/smhpapers/347

Research Online is the open access institutional repository for the University of Wollongong. For further information contact the UOW Library: research-pubs@uow.edu.au 


\title{
Selective transport of Cadmium by PVC/Aliquat 336 polymer inclusion membranes (PIMs): the role of membrane composition and solution chemistry
}

\begin{abstract}
This study investigated the extraction and stripping performance of PIMs consisting of PVC and Aliquat 336. Extraction and stripping of three representative heavy metals - namely $\mathrm{Cd} 2+, \mathrm{Cu} 2+$, and $\mathrm{Zn} 2+-$ by the synthesized membranes were evaluated as a function of sodium chloride concentration and under different stripping solutions ( $0.01 \mathrm{M} \mathrm{HNO3,} \mathrm{Milli-Q}$ water, $0.01 \mathrm{M} \mathrm{HCl}$, and $0.01 \mathrm{M} \mathrm{NaOH}$ ), respectively. Results reported here indicate that the formation of negatively charged metal chloride complex species was responsible for the extraction of the target metal to PIMs. Experimental results and thermodynamic modeling of the speciation of chloro metal complexes further confirm that the extraction selectivity between $\mathrm{Cd} 2+, \mathrm{Cu} 2+$, and $\mathrm{Zn} 2+$ can be controlled by regulating the chloride concentration of the feed solution. An acidic solution without any chloride was the most effective stripping solution, followed by Milli-Q water, and a diluted hydrochloric acid solution. On the other hand, the stripping of metals from PIMs did not occur when a basic stripping solution was used.
\end{abstract}

\section{Keywords}

membrane, composition, solution, chemistry, selective, pvc, aliquat, 336, polymer, inclusion, transport, membranes, cadmium, pims, role, GeoQuest

\section{Disciplines}

Medicine and Health Sciences | Social and Behavioral Sciences

\section{Publication Details}

Adelung, S., Lohrengel, B. \& Nghiem, L. Duc. (2012). Selective transport of Cadmium by PVC/Aliquat 336 polymer inclusion membranes (PIMs): the role of membrane composition and solution chemistry. Membrane Water Treatment, 3 (2), 123-131. 


\title{
Selective transport of Cadmium by PVC/Aliquat 336 polymer inclusion membranes (PIMs): the role of membrane composition and solution chemistry
}

\author{
Sandra Adelung ${ }^{1,2}$, Burkhard Lohrengel ${ }^{2}$ and Long Duc Nghiem*1 \\ ${ }^{1}$ Environmental Engineering, University of Wollongong, NSW 2522, Australia \\ ${ }^{2}$ Department of Process Engineering and Environmental Technology, Faculty of Engineering 2, \\ Heilbronn University, Heilbonn, Germany
}

(Received September 12, 2011, Revised February 18, 2012, Accepted February 20, 2012)

\begin{abstract}
This study investigated the extraction and stripping performance of PIMs consisting of PVC and Aliquat 336. Extraction and stripping of three representative heavy metals - namely $\mathrm{Cd}^{2+}, \mathrm{Cu}^{2+}$, and $\mathrm{Zn}^{2+}$ - by the synthesized membranes were evaluated as a function of sodium chloride concentration and under different stripping solutions $\left(0.01 \mathrm{M} \mathrm{HNO}_{3}\right.$, Milli-Q water, $0.01 \mathrm{M} \mathrm{HCl}$ and $0.01 \mathrm{M} \mathrm{NaOH}$ ), respectively. Results reported here indicate that the formation of negatively charged metal chloride complex species was responsible for the extraction of the target metal to PIMs. Experimental results and thermodynamic modeling of the speciation of chloro metal complexes further confirm that the extraction selectivity between $\mathrm{Cd}^{2+}, \mathrm{Cu}^{2+}$ and $\mathrm{Zn}^{2+}$ can be controlled by regulating the chloride concentration of the feed solution. An acidic solution without any chloride was the most effective stripping solution, followed by Milli-Q water, and a diluted hydrochloric acid solution. On the other hand, the stripping of metals from PIMs did not occur when a basic stripping solution was used.
\end{abstract}

Keywords: polymer inclusion membranes (PIMs); metal extraction; base polymer; PVC; Aliquat 336

\section{Introduction}

Polymer inclusion membranes (PIMs) present an exciting and novel approach for the separation of metallic and small organic ions from aqueous solutions (St John et al. 2011, O'Rourke et al. 2011, Nghiem et al. 2006). Potential applications of PIMs include metal recovery in mineral processing and the fabrication of passive sampling devices (Nghiem et al. 2006). In fact, it has been suggested that PIMs may complement current liquid-liquid extraction techniques, which are commonly referred to as solvent extraction (SX) techniques. Although current state of the art SX processes are very efficient and cost effective (Ritcey 2006), the operation of SX facilities presents considerable occupational and environmental hazards. This is because SX techniques require large quantities of flammable and toxic organic solvents (known as diluents) to dissolve extraction reagents (or extractants). These chemicals are usually corrosive, toxic, and highly volatile (O'Rourke et al. 2009, Marinova and Yankov 2009). PIMs minimize the risk of releasing these chemicals into the environment by encapsulating the extractant in a polymer matrix (Nghiem et al. 2006). In fact, the stability of PIMs has been recently confirmed by Cho et al. (2011) who showed no leaching of the extractant or any significant loss of

\footnotetext{
* Corresponding author, Mr., E-mail: longn@uow.edu.au
} 
performance of a PVC/Aliquat 336 PIM after repetitive cycles of extraction and de-extraction of thiocyanate. This removes the in-situ need for large inventories of solvents and reduces the environmental exposure to extractants in their mobile form (Nghiem et al. 2006). Another unique and potential application of PIMs is the fabrication of passive sampling devices for trace levels of metal ions and small organic molecules. Indeed, PIMs have been used in chemical sensing for more than 30 years in the form of polymer membrane ion-selective electrodes (ISEs) (Cattrall 1997). In 1970, it was demonstrated that calcium complexing reagents could be immobilized into PVC to produce a polymer film for the fabrication of ISEs for the detection of calcium (Moody 1970). Since then, numerous PVC-based membranes have been developed for the potentiometric sensing of various cations and anions. Such membranes for use in potentiometry have also been termed "gelled liquid membranes" and "entangled liquid membranes" (Cattrall 1997). Also in the 1970s, Bloch et al. (1967) demonstrated that PVC-based membranes could also be used for metal ion separation although the requirements for the membrane characteristics were somewhat different for the two applications.

PIMs designed for facilitated transport of metals consist of the three main components; a polymer, a plasticizer and an extractant. These three components each contribute to the overall performance and physiochemical characteristics of the membrane. A delicate balance exists between the components of PIMs and this balance governs the performance of the membrane during its use in extracting metallic ions and small organic molecules (Nghiem et al. 2006). Although there have been numerous dedicated investigations examining the interplay amongst these components, more research is required to elucidate the extraction mechanisms of metallic ions and small organic molecules by PIMs (Nghiem et al. 2006). Liquid-liquid extraction of various base metals from solution containing high concentration of chloride using quaternary ammonium salts including Aliquat 336 has been widely studied by numerous researchers (see for examples: Juang et al. 2004, Sato et al. 1984, Grudpan and Taylor 1984). The extraction mechanism has been shown to involve negatively charge chloro metal complexes (Juang et al. 2004). The extraction mechanism of base metals such as cadmium to PVC/Aliquat PIMs is thought to be similar to that in a liquid-liquid extraction process, however to date, this premise has not been verified. Pont et al. (2008) studied the extraction of $\mathrm{Cd}$ to PIMs made of cellulose triacetate, Aliquat 336 and o-nitrophenyl octyl ether and reported that extraction could only occur in a chloride matrix of $0.1 \mathrm{M}$ or higher. They hypothesized that $\mathrm{CdCl}_{3}{ }^{-}$ was responsible for the extraction of $\mathrm{Cd}$ to PIMs in a similar fashion to that of SX using Aliquat 336 as the extractant. However, they did not explain why the rate of extraction did not significantly vary with chloride concentration in the range from 0.1 to $2 \mathrm{M}$ although the percentage of the $\mathrm{CdCl}_{3}{ }^{-}$

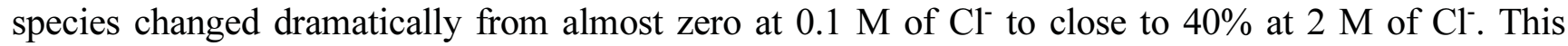
paper aims to examine the extraction and stripping of three base metals namely cadmium, copper, and zinc to and from PVC/Aliquat 336 PIMs. Variations in the composition of the base polymer PVC and the extractant Aliquat 336 as well as the solution chemistry were related to the extraction and de-extraction (stripping) properties of PIMs. The obtained data were then used to delineate the extraction of base metals to PVC/Aliquat PIMs.

\section{Materials and methods}

\subsection{Reagents}

Technical grade Aliquat 336 (tricaprylylmethylammonium chloride) was purchased from Sigma- 
Aldrich (Australia) and was used without any further purification. A high molecular weight (MW) PVC (Sigma-Aldrich, Australia) was used as the base polymer. The weight average MW and number average MW of this PVC were 233 and $99 \mathrm{kDa}$, respectively. HPLC grade tetrahydrofuran (THF) was purchased from BDH (Australia). All other chemicals used in this study were of analytical grade from Sigma-Aldrich (Australia). Cadmium (II), copper (II), and zinc (II) solutions, used in the membrane extraction experiments and for calibration purposes, were prepared from their corresponding nitrate salts. Laboratory grade Milli-Q water (Millipore, Australia) was used for the preparation of all solutions.

\subsection{Preparation of PVC/Aliquat 336 membranes}

The membranes were prepared by dissolving the base polymer PVC and the extractant Aliquat 336 chloride in approximately $10 \mathrm{~mL}$ THF solvent as previously described elsewhere (Upitis et al. 2009). The total mass of PVC and Aliquat 336 was $600 \mathrm{mg}$. The PVC, Aliquat, and THF mixture was vigorously mixed using a stirring bar for approximately 1 hour until the solution became clear. The solution was then poured into a petri glass dish. The petri dish was covered with $0.45 \mu \mathrm{m}$ filter paper to control the evaporation rate of THF. After the THF has evaporated, the membrane was then peeled from the petri dish and stored in dry condition for further experiments.

\subsection{Extraction and stripping protocol}

Extraction was conducted in bath mode. The membrane was cut into small pieces of approximately $1 \mathrm{~cm}^{2}$ each and placed in a beaker containing $250 \mathrm{~mL}$ of an appropriate extraction solution. The extraction solution contained either $\mathrm{Cd}(\mathrm{II}), \mathrm{Cu}$ (II) or $\mathrm{Zn}(\mathrm{II})$ and a specified concentration of $\mathrm{NaCl}$. The solutions were stirred continuously at a constant speed and $1 \mathrm{~mL}$ of aliquot was taken at a specific interval for Atomic Adsorption Spectrometry analysis (Varian Carrier, AAS 300). Calibration curves using the standard $\mathrm{Cd}(\mathrm{II}), \mathrm{Cu}(\mathrm{II})$ and $\mathrm{Zn}$ (II) solutions were obtained with typical $\mathrm{R}^{2}$ values of more than 0.99 in all analysis. All samples were analysed in triplicate and the standard deviation of 3 replicate measurements was always less than $3 \%$. At the end of the extraction experiment, the membrane samples were removed from the extraction solution using a pair of tweezers. After removing all excessive liquid, the membrane samples were then placed into a beaker containing 250 $\mathrm{mL}$ of a stripping solution, containing either $0.01 \mathrm{M} \mathrm{HNO}_{3}$, Milli-Q water, $0.01 \mathrm{M} \mathrm{HCl}$ or $0.01 \mathrm{M}$ $\mathrm{NaOH}$. The solutions were also stirred continuously at a constant speed and $1 \mathrm{~mL}$ of aliquot was taken at a specific interval for analysis. During the extraction and stripping experiments, the test solution was covered with paraffin film to avoid any evaporation.

\subsection{Scanning electron microscope}

The PVC/Aliquat 336 membranes were visually characterised with a JSM-6490LA (JEOL Japan) scanning electron microscope (SEM). To prepare for SEM analysis, the membrane sample was frozen instantaneously by dipped into liquid nitrogen. The membrane was then snapped using a pair of tweezers to reveal the cross section. Prior to SEM analysis, the membrane samples were coated with a thin layer of gold using a gold sputter. 
(a)

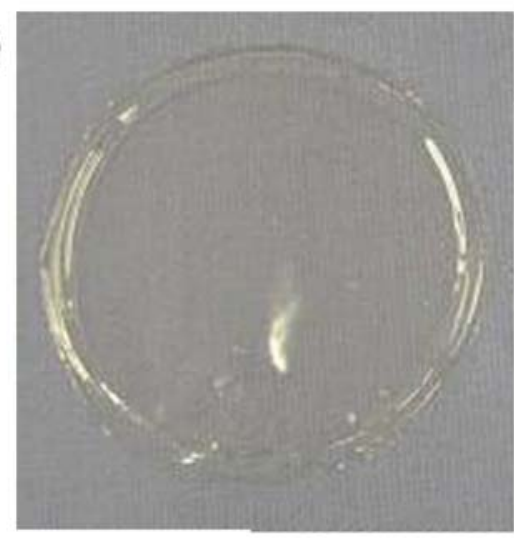

(b)

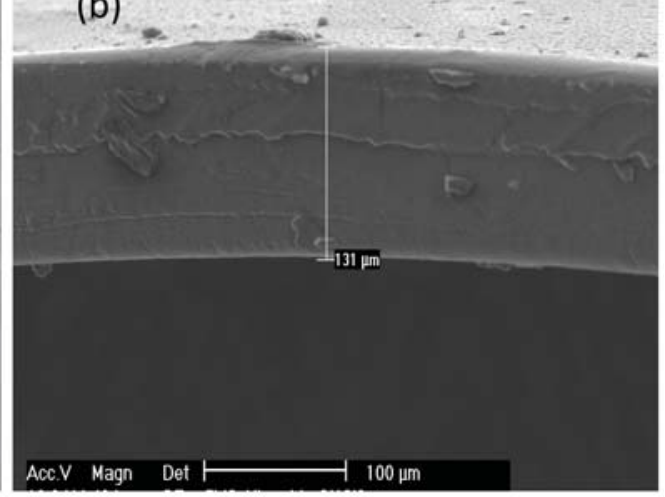

Fig. 1 Aliquat/PVC polymer inclusion membranes: (a) a real scale image of the membrane and (b) an SEM micrograph of the membrane cross section

\section{Results and discussion}

\subsection{Membrane preparation}

The combination of 40-70\% PVC with the balance of Aliquat 336 resulted in a thin, transparent, and flexible film (Fig. 1(a)). The weight of each membrane was measured and was consistently within $5 \%$ of the initial weight $(600 \mathrm{mg})$ of the combined PVC and Aliquat mixture. The small deviation between the final weight of the membrane and that of the initial ingredient can be attributed to solution losses during the fabrication procedure of PIMs particularly when transferring the PVC/ Aliquat/THF solution from the beaker to the petri dish. SEM analysis revealed that the obtained membrane has a homogeneous internal structure. A typical SEM image of the membrane is shown in Fig. 1(b). No correlation between the actual PVC/Aliquat composition and the membrane thickness could be observed. These PVC/Aliquat membranes had a uniform thickness of approximately $130 \mu \mathrm{m}$.

\subsection{Effects of Aliquat content on Cd(II) extraction}

Extraction experiments were conducted with aqueous solutions containing $\mathrm{Cd}(\mathrm{II}), \mathrm{Cu}(\mathrm{II})$, or $\mathrm{Zn}$ (II) in $0.05 \mathrm{M}$ of $\mathrm{NaCl}$. These base metals are known to readily complex with chloride. Results reported in Fig. 2 show that Cd(II) was favourably extracted by PVC/Aliquat PIMs. Since Aliquat 336 is the extractant and the base polymer PVC only provides mechanical support to the membranes, not surprisingly, the rate of extraction increased as the Aliquat content in PIMs increased (Fig. 2(a)). Correspondingly, the rate of de-extraction using Milli-Q water as the stripping solution also increased as the Aliquat content in PIMs increased (Fig. 2(b)). In contrast, no extraction of both $\mathrm{Cu}(\mathrm{II})$ and $\mathrm{Zn}$ (II) could be observed when the extraction solution contained $0.05 \mathrm{M}$ of $\mathrm{NaCl}$ (data not shown). The rate of $\mathrm{Cd}(\mathrm{II})$ extraction to $\mathrm{PVC} /$ Aliquat PIMs in a $2 \mathrm{M} \mathrm{HCl}$ solution previously observed by Upitis et al. (2009) was significantly higher than that reported in Fig. 2(a) where the feed solution contained $0.05 \mathrm{M} \mathrm{NaCl}$. Chloride is abundant in seawater and some groundwater. Results reported here demonstrate the potential of PVC/Aliquat PIMs for the fabrication of passive sampling devices for heavy metals contamination such as cadmium in seawater and brackish water in addition to their applications in mineral processing. In good agreement with the current study, Upitis et al. (2009) 


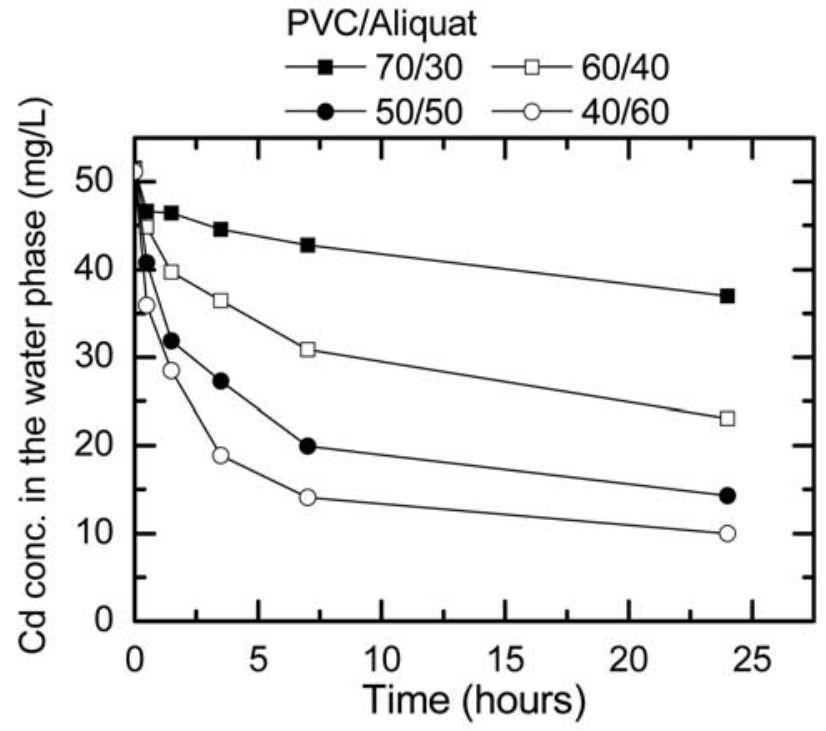

(a) Extraction

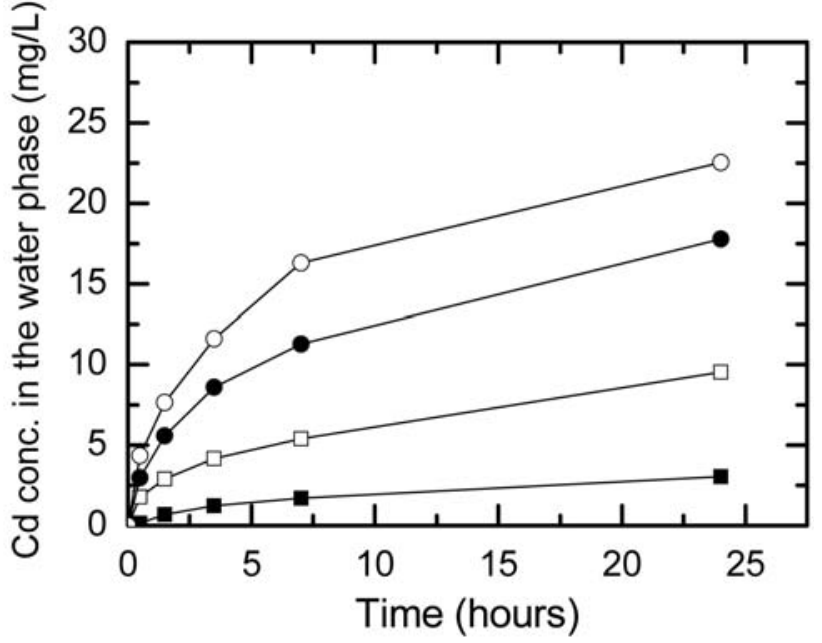

(b) De-extraction

Fig. 2 (a) Extraction and (b) de-extraction (stripping) kinentics of cadmium to PIMs with different PVC and Aliquat 336 contents. Extraction solution contained $50 \mathrm{mg} / \mathrm{L} \mathrm{Cd}$ in $0.05 \mathrm{M} \mathrm{NaCl}$ solution. Milli-Q water was used as the stripping solution

also reported negligible extraction of $\mathrm{Cu}(\mathrm{II})$ into PVC/Aliquat PIMs in a $2 \mathrm{M} \mathrm{HCl}$ solution. Upitis et al. (2009) speculated that the extraction selectivity of $\mathrm{Cd}(\mathrm{II})$ over $\mathrm{Cu}$ (II) could be attributed to the occurrence of different metal chloride complex species and that only trichloro metal complex could be extracted by PVC/Aliquat PIMs. To substantiate this hypothesis, extraction experiments were conducted with aqueous solutions containing $\mathrm{Cd}(\mathrm{II}), \mathrm{Cu}(\mathrm{II})$, or $\mathrm{Zn}(\mathrm{II})$ in $0.05,0.1$ and $3 \mathrm{M}$ of $\mathrm{NaCl}$ and the results are presented in Figs. 3(a)-3(c), respectively. The distribution of different metallic ions in a chloride matrix was also modeled using the ChemEQL (version 3.1) thermodynamic modeling software developed by EAWAG (Figs. 3(d)-3(f)).

The extraction of the three base metals investigated here correlates very well to their speciation in the chloride matrix (Fig. 3). Significant extraction of Cd(II) PVC/Aliquat PIMs can be observed when the extraction solution contain $\mathrm{NaCl}$ in the range from 0.05 to $3 \mathrm{M}$. In good agreement with the above discussion, $\mathrm{Cu}$ (II) was not extracted to the PVC/Aliquat PIMs regardless of the concentration of chloride in the extraction matrix (Fig. 3(b)) and this observation can be attributed to the absence of any negatively charged copper chloride complex species within the chloride concentration range from 0.05 to $3 \mathrm{M}$ (Fig. 3(e)). Interestingly, while the extraction of $\mathrm{Zn}$ (II) did not occur when the extraction solution contained less than $0.1 \mathrm{M}$ of $\mathrm{NaCl}$, significant $\mathrm{Zn}$ (II) extraction could be observed at high $\mathrm{NaCl}$ concentration $(3 \mathrm{M}$ ). Once again, the speciation of zinc chloride complex can be used to explain this observation. At below $0.1 \mathrm{M}$ of $\mathrm{NaCl}$, the trichloro zinc complex does not exist (Fig. 3(f)) thus the extraction of $\mathrm{Zn}(\mathrm{II})$ to PVC/Aliquat PIMs could not occur at diluted chloride concentration (less than $0.1 \mathrm{M}$ ). At higher chloride concentration, the trichloro zinc complex could be formed and thus the extraction of $\mathrm{Zn}(\mathrm{II})$ to PVC/Aliquat PIMs could only occur at high chloride concentration (Fig. 3(c)).

It is noteworthy that the rate of $\mathrm{Cd}(\mathrm{II})$ extraction to PVC/Aliquat PIMs only marginally increased as the concentration of $\mathrm{NaCl}$ in the extraction solution increased from 0.05 to $0.1 \mathrm{M}$. No discernible 

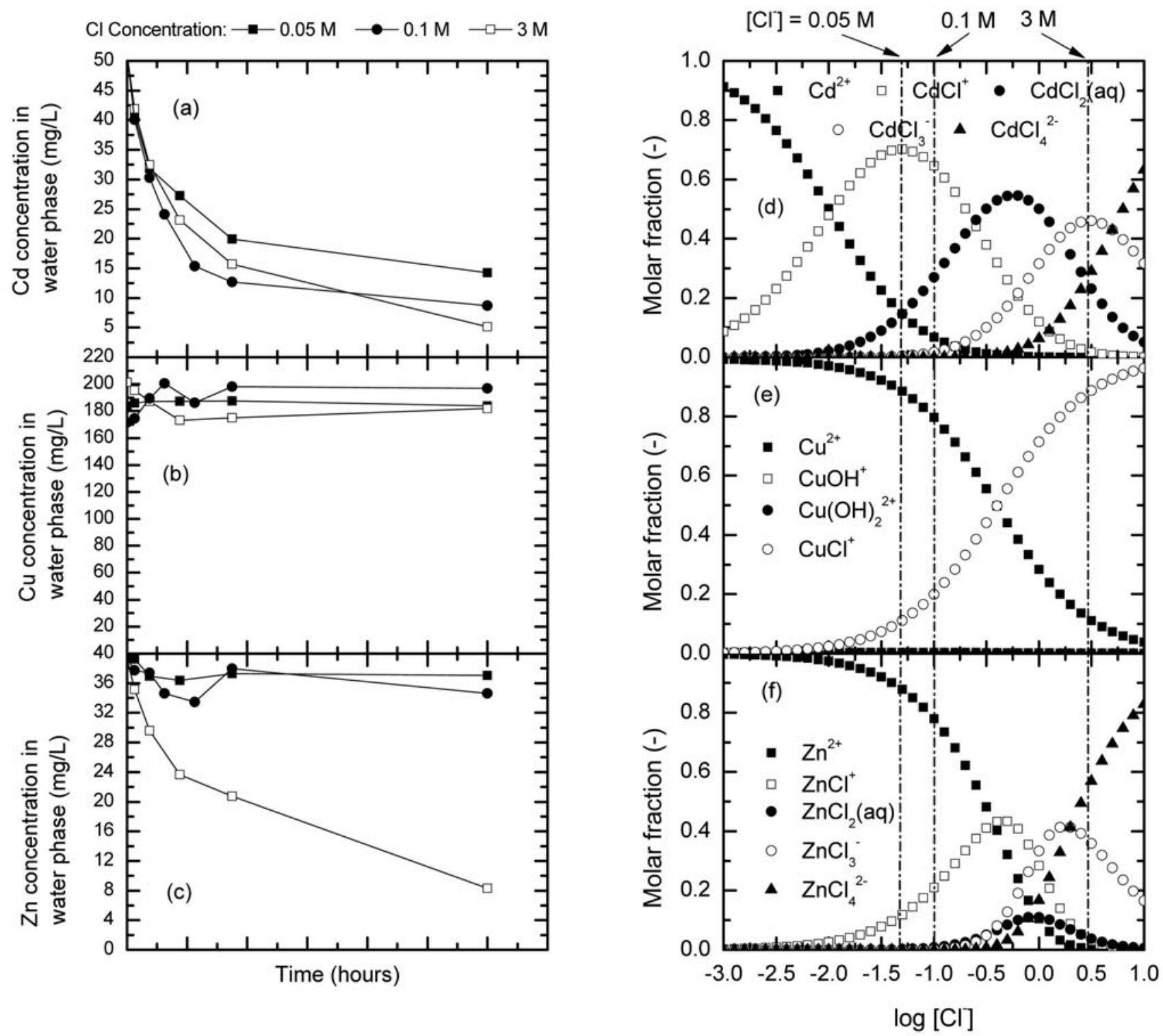

Fig. 3 Extraction of (a) $\mathrm{Cd}$ (II), (b) $\mathrm{Cu}$ (II), and (c) $\mathrm{Zn}$ (II) into PVC/Aliquat PIMs (wt $/ \mathrm{wt}=50 \% / 50 \%$ ) from solutions containing different $\mathrm{NaCl}$ concentration. The speciation of (d) cadmium, (e) cupper, and (f) zinc chloro complex as a function of $\mathrm{NaCl}$ concentration (solution chemistry is the same as the extraction experiments)

increase in the extraction rate of $\mathrm{Cd}(\mathrm{II})$ to $\mathrm{PVC} / \mathrm{Aliquat} \mathrm{PIMs}$ could be observed as the $\mathrm{NaCl}$ concentration increased from 0.1 to $3 \mathrm{M}$. On the other hand, over the same $\mathrm{NaCl}$ concentration range, the molar fraction of the trichloro and tetrachloro cadmium complex species increased dramatically. Results reported here suggest that the kinetic of the formation of base metal chloride complex is much faster than the rate of PIM extraction and that only a minute amount of extractable species is enough for the extraction process to occur. The reported results also highlight the potential of regulating the concentration of chloride to manipulate the extraction selectivity between certain base metals. Data reported in Fig. 3 does not provide sufficient evidence to ascertain the role of tetrachloro metal complex in the extraction process. Nevertheless, assuming that trichloro metal complex is the 
only species involved in the extraction process, the extraction of base metal to PVC/Aliquat PIMs (taking cadmium as an example) can be described as

$$
\mathrm{CdCl}_{3}+\mathrm{CH}_{3}\left(\mathrm{C}_{8} \mathrm{H}_{17}\right)_{3} \mathrm{~N}^{+} \mathrm{Cl} \Leftrightarrow \overline{\mathrm{CH}_{3}\left(\mathrm{C}_{8} \mathrm{H}_{17}\right)_{3} \mathrm{~N}^{+} \mathrm{CdC \Gamma _{3 }}}+\mathrm{Cl}
$$

Eq. (1) suggests that for each trichloro cadmium complex molecule extracted to the membrane, one chloride molecule will be released into the aqueous phase. Eq. (1) is also consistent with the extraction mechanism of cobalt to PVC/Aliquat PIMs recently proposed by Kagaya et al. (2011). However, the stripping (or de-extraction) of cadmium from PVC/Aliquat PIMs cannot be taken in the reverse order. Further discussion of the stripping process is available in the next section.

\subsection{Stripping of cadmium from PVC/Aliquat PIMs}

Four different stripping solutions namely Milli-Q water, $0.01 \mathrm{M}$ of $\mathrm{NaOH}, 0.01 \mathrm{M}$ of $\mathrm{HCl}$ and $0.01 \mathrm{M}$ of $\mathrm{HNO}_{3}$ were used to evaluate the de-extraction of cadmium from PVC/Aliquat PIMs. The extraction of cadmium to PVC/Aliquat (wt/wt $=50 \% / 50 \%$ ) PIM was first conducted and the results were highly reproducible (Fig. 4(a)). Cadmium could not be stripped from the membrane when 0.01 $\mathrm{M} \mathrm{NaOH}$ was used as the stripping solution. This is possibly because of the low solubility of cadmium in a basic condition. The stripping of cadmium from the membrane could be observed with $0.01 \mathrm{M} \mathrm{HCl}$. However, it is notable that the stripping efficiency was lower than that with Milli-Q water. In fact, the stripping of cadmium from the membrane was most effective with a $0.01 \mathrm{M}$ $\mathrm{HNO}_{3}$ solution. Results presented in Fig. 4 indicate that the stripping of cadmium can only occur in acidic or neutral condition. In addition, the presence of chloride is actually unfavourable for the stripping process. The stripping of cadmium from PVC/Aliquat PIMs is hypothesized as below

$$
\begin{aligned}
& \overline{\mathrm{CH}_{3}\left(\mathrm{C}_{8} \mathrm{H}_{17}\right)_{3} \mathrm{~N}^{+} \mathrm{CdCl}_{3}} \Leftrightarrow \mathrm{CH}_{3}\left(\mathrm{C}_{8} \mathrm{H}_{17}\right)_{3} \mathrm{~N}^{+} \mathrm{Cl}+\mathrm{CdCl}+\mathrm{Cl} \\
& \overline{\mathrm{CH}_{3}\left(\mathrm{C}_{8} \mathrm{H}_{17}\right)_{3} \mathrm{~N}^{+} \mathrm{CdC \Gamma _{3 }}} \Leftrightarrow \mathrm{CH}_{3}\left(\mathrm{C}_{8} \mathrm{H}_{17}\right)_{3} \mathrm{~N}^{+} \mathrm{Cl}+\mathrm{Cd}^{2+}+2 \mathrm{Cl}
\end{aligned}
$$

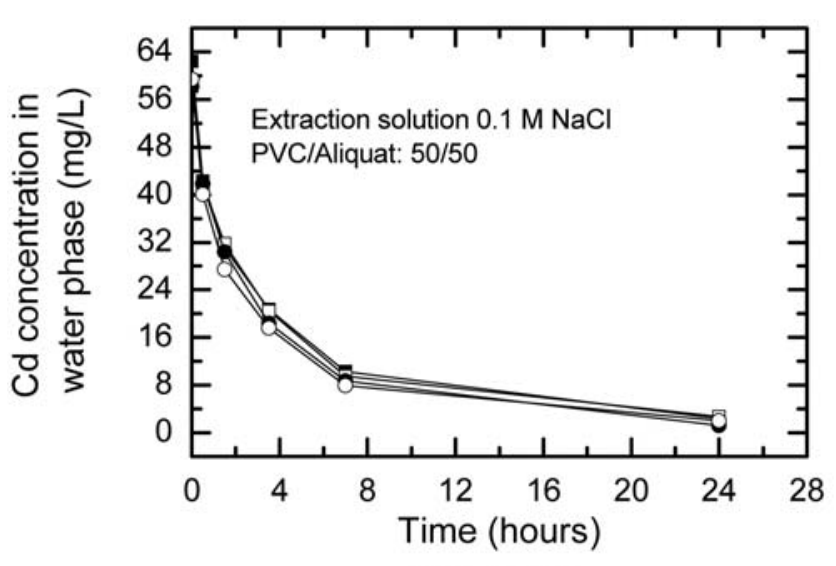

(a) Extraction

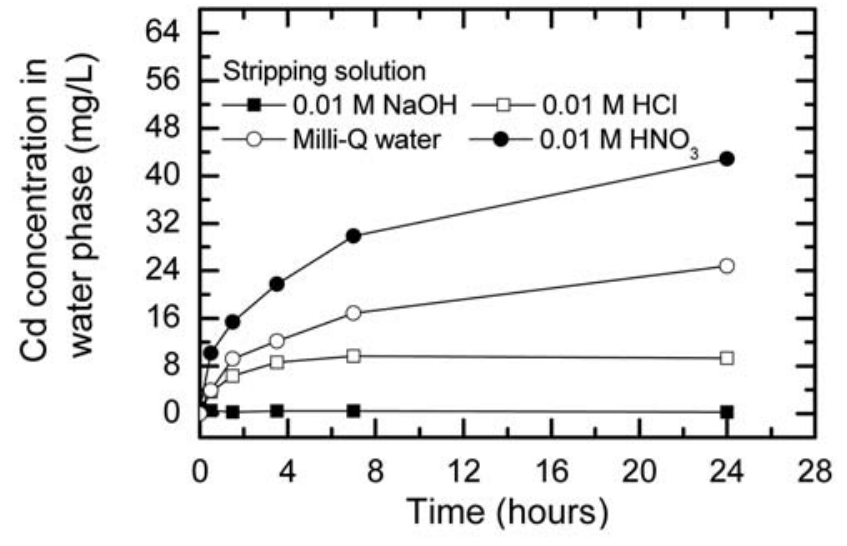

(b) De-extraction

Fig. 4 (a) Extraction and (b) de-extraction (stripping) kinentics of cadmium to PVC/Aliquat PIMs (wt/wt= $50 \% / 50 \%$ ) 
As can be seen in Eqs. (2) and (3), the stripping of cadmium generates chloride, and thus in good agreement with the discussion above, the presence of chloride in the stripping solution is unfavourable. Based on the extraction and stripping mechanisms proposed in Eqs. (1)-(3), it appears that facilitative transport of cadmium through PVC/Aliquat PIMs can be achieved with a chloride concentration gradient across the membrane in a co-current transport mode. Facilitated transport of base metals through PVC/Aliquat PIMs is beyond the scope of this current investigation but will be reported in a future study.

\section{Conclusions}

This study demonstrated the fabrication of PVC/Aliquat PIMs for selective extraction of Cd(II) over other base metals. The rate of $\mathrm{Cd}(\mathrm{II})$ extraction from a chloride matrix increased as the Aliquat content in PIMs increased. Results reported here showed that the trichloro and possible tetrachloro complex species were responsible for the extraction of base metals into PVC/Aliquat PIMs. Therefore, the selectivity of $\mathrm{Cd}(\mathrm{II})$ over $\mathrm{Cu}$ (II) and $\mathrm{Zn}$ (II) can be controlled by regulating the chloride concentration in the extraction solution. The de-extraction of $\mathrm{Cd}(\mathrm{II})$ was most effective when the stripping solution was acidic and in the absence of any chloride.

\section{References}

St John, A.M., Best, S.P., Wang, Y., Tobin, M.J., Puskar, L., Siegele, R., Cattrall, R.W. and Kolev, S.D. (2011), "Micrometer-scale 2D mapping of the composition and homogeneity of polymer inclusion membranes", Aust. J. Chem., 64(7), 930-938.

O’Rourke, M., Duffy, N., de Marco, R. and Potter, I. (2011), "Electrochemical impedance spectroscopy-a simple method for the characterization of polymer inclusion membranes containing Aliquat 336", Membranes, 1(2), 132-148.

Nghiem, L.D., Mornane, P., Potter, I.D., Perera, J.M., Cattrall, R.W. and Kolev, S.D. (2006), "Extraction and transport of metal ions and small organic compounds using polymer inclusion membranes (PIMs)", $J$. Membrane Sci., 281(1-2), 7.

Ritcey, G.M. (2006), "Solvent Extraction in Hydrometallurgy: Present and Future", Tsinghua Science \& Technology, 11(2), 137-152.

O'Rourke, M., Cattrall, R.W., Kolev, S.D. and Potter, I.D. (2009), "The extraction and transport of organic molecules using polymer inclusion membranes", Solvent Extr. Res. Development, 16, 1-12.

Marinova, N.A. and Yankov, D.S. (2009), "Toxicity of some solvents and extractants towards Lactobacillus casei cells", Bulg. Chem. Commun., 41(4), 368-373.

Cho, Y., Xu, C., Cattrall, R.W. and Kolev, S.D. (2011), "A polymer inclusion membrane for extracting thiocyanate from weakly alkaline solutions", J. Membrane Sci., 367(1-2), 85-90.

Cattrall, R.W. (1997), Chemical sensors, in Oxford Chemistry Primers, R.G. Compton, Editor. Oxford University Press: New York.

Moody, G.J., Oke, R.B. and Thomas, J.D.R. (1970), "A calcium-sensitive electrode based on a liquid ion exchanger in a poly(vinyl chloride) matrix", Analyst, 95(1136), 910-918.

Bloch, R., Finkelstein, A., Kedem, O. and Vofsi, D. (1967), "Metal-ion separation by dialysis through solvent membranes", Ind. Eng. Chem. Prod. Res. Dev., 6(2), 231-237.

Juang, R.S., Kao, H.C. and Wu, W.H. (2004), "Analysis of liquid membrane extraction of binary Zn(II) and $\mathrm{Cd}(\mathrm{II})$ from chloride media with Aliquat 336 based on thermodynamic equilibrium models", J. Membrane Sci., 228(2), 169-177.

Sato, T., Shimomura, T., Murakami, S., Maeda, T. and Nakamura, T. (1984), "Liquid-liquid extraction of divalent 
manganese, cobalt, copper, zinc and cadmium from aqueous chloride solutions by tricaprylmethylammonium chloride", Hydrometallurgy, 12(2), 245-254.

Grudpan, K. and Taylor, C.G. (1984), "Use of aliquat-336 for the extraction of cadmium from aqueous solutions", Analyst, 109(5), 585-588.

Pont, N., Salvadó, V. and Fontàs, C. (2008), "Selective transport and removal of Cd from chloride solutions by polymer inclusion membranes", J. Membrane Sci., 318(1-2), 340-345.

Upitis, A., Peterson, J., Lukey, C. and Nghiem, L.D. (2009), "Metallic ion extraction using polymer inclusion membranes (PIMs): Optimising physical strength and extraction rate", Desal. Wat. Treat., 6(1-3), 41-47.

Kagaya, S., Cattrall, R.W. and Kolev, S.D. (2011), "Solid-phase extraction of cobalt(II) from lithium chloride solutions using a poly(vinyl chloride)-based polymer inclusion membrane with Aliquat 336 as the carrier", Anal. Sci., 27(6), 653-657.

$C C$ 